\title{
AS ORATIONES I, II E III DE SÍMACO E SEU IMPACTO NO REINADO DE VALENTINIANO I
}

Carlos Eduardo Schmitt*

\begin{abstract}
RESUMO: Quinto Aurélio Símaco Eusébio (c. 340-402) possui uma extensa obra, da qual chegaram à contemporaneidade mais de 900 cartas (epistolae), 49 informes (relationes) e 8 discursos (orationes). Suas obras de maior destaque são as Orationes I, II e III, proferidas entre 369-370, e sua Relatio III, escrita durante seu tempo como prefeito de Roma em 384. Tais obras lhe renderam a fama de melhor orador de seu tempo ainda em vida. Nosso trabalho tem como objetivo expor o impacto que as Orationes I, II e III tiveram na carreira do orador e na relação entre o Senado e o reinado de Valentiniano I. A partir de suas Orationes, ressaltaremos a delicada missão do orador, enviado de Roma à Tréveris para servir como ponte entre o Senado e o imperador.
\end{abstract}

Palavras-Chave: Símaco; Orationes; Valentiniano I

\section{SYMMACHUS' ORATIONES I, II AND III AND ITS IMPACT IN THE KINGDOM OF VALENTINIAN I}

ABSTRACT: Quintus Aurelius Symmachus Eusebius (c 340-402) has an extensive work, from which more than 900 letters (epistolae), 49 reports (relationes) and 8 discourses (orationes) survived. His most outstanding works are Orationes I, II and III, pronounced between 369-370, and his Relatio III, written during his time as praefectus of Rome in 384. Such works earned him the fame of the best speaker of his time being still alive. Our paper aims to expose the impact that Orationes I, II and III had on the speaker's career and on the relation between the Senate and the reign of Valentinian I. From his Orationes we will highlight the delicate mission of the speaker, sent from Rome to Trier to serve as a bridge between the Senate and the emperor.

KEYWORDS: Symmachus; Orationes; Valentinian I.

\section{LAS ORATIONES I, II E III DE SÍMACO Y SU IMPACTO EN EL REINADO DE VALENTINIANO I}

RESUMEN: Quinto Aurelio Símaco Eusebio (c. 340-402) tiene una extensa obra, de la cual chegaron a la contemporaneidad más de 900 cartas (epistolae), 49 informes (relationes) e 8 discursos (orationes). Sus obras de mayor destaque son las Orationes I,

\footnotetext{
* Doutorando pela Universidade de São Paulo. E-mail: carlos.schmitt90@gmail.com
} 
II y III, pronunciadas entre el 369-370, y su Relatio III, escrita durante su tiempo como prefecto de Roma en 384. Tales obras le rindieron la fama de mejor orador de su tiempo aún en vida. Nuestro artículo tiene como objetivo exponer el impacto que las Orationes I, II y III tuvieron en la carrera del orador y en la relación entre el Senado y el reinado de Valentiniano I. A partir de sus Orationes, resaltaremos la delicada misión del orador, enviado de Roma a Tréveris para servir como puente entre el Senado y el emperador.

Palavras Clave: Símaco; Orationes; Valentiniano I.

\section{INTRODUÇÃO}

José Antonio Gallego (2003, p. 153) esclarece que a obra mais famosa de Símaco foi seu informe terceiro, apesar de que durante a Idade Média as epistolae foram suas obras mais valorizadas, sendo utilizadas como modelo para escrever uma carta. Contudo, em seu próprio tempo ele era famoso por ser um grande orador. É por isso que Gallego (2003, p. 154) pondera como injusto o que a história fez com Símaco. Apenas oito de seus discursos chegaram até nós, sendo que estes são dos inícios de sua carreira, além de estarem num manuscrito palimpsesto com grandes lacunas. Deve-se ter presente também que "Símaco é o último grande orador romano, se excetuarmos os escritores cristãos." (GALLEGO, 2003, p. 154). Em outras palavras, Símaco é o último grande orador da religião tradicional romana.

Cristiana Sogno (2006, p. viii) faz uma reconstrução da carreira política de Símaco, através de uma análise minuciosa de seus escritos. Ele ocupa uma posição peculiar entre os autores latinos, pela quantidade de escritos que nos chegaram. A autora defende que a razão pelo desconhecimento de Símaco por parte dos estudantes de Clássicas e de História Antiga é o fato de não existir uma tradução completa do corpus simaquiano em nenhuma língua moderna. Sogno clarifica também que a edição de Otto Seeck do século XIX continua sendo o modelo do texto.

Sogno (2006, p. 1) clarifica que a primeira fase da carreira de Símaco está bem documentada em suas orationes. Sua nominação como embaixador senatorial em 368 foi um marco em sua vida, sendo que sua reputação como orador foi estabelecida na corte de Valentiniano I, tornando-se uma ponte entre o Senado e o imperador.

Apesar de que Símaco tenha a fama de ser um grande orador, suas orationes desapareceram, até seu redescobrimento no século XIX. Sabe-se que Símaco ficou conhecido por ser um bastião em defesa da religião tradicional romana, sobretudo durante seu período como Prefeito de Roma, por volta de 384. E Sogno (2006, p. 1), sem perder a oportunidade, relata uma "ironia do destino", sendo que foi um cardeal da Igreja Católica Romana, Angelo Mai, quem descobriu e publicou os fragmentos de suas orationes em 1815. Tratava-se de um palimpsesto, onde por cima havia uma tradução latina das atas do Concílio de Calcedônia. $\mathrm{O}$ cardeal destruiu o documento para que as orationes pudessem ser recuperadas. Apesar disso, Sogno (2006, p. 2) constata como esses discursos de Símaco são ainda pouco estudados, em comparação com outros escritos seus, como suas epistolae. Esses oito discursos são apenas uma parte de toda a produção simaquiana. Há também um panegírico em honra do usurpador Máximo, que por razões óbvias não foi publicada.

\footnotetext{
1 "Símaco es el último gran orador romano, si dejamos a un lado a los escritores cristianos."
} 


\section{ORATIONES I, II E III}

Foi no inverno do ano 368-369 que Símaco, naquele tempo um jovem senador que iniciava sua carreira política, foi enviado de Roma à Tréveris com o objetivo de dirigir uma laudatio, uma oração de louvor a Valentiniano I, por motivo de seus cinco anos de reinado (Quinquennalia). Sogno (2006, p. 2) destaca que tal missão não significava apenas um reconhecimento por parte do Senado de seus dotes retóricos, mas constituía também uma oportunidade ímpar para crescer na carreira política e fazer amigos na corte.

Apesar de ser um momento festivo, Sogno (2006, pp. 1-2) esclarece que constituía uma situação delicada. Até o momento, Valentiniano I não havia estado em Roma e essa era a primeira vez que ele se encontraria com uma delegação senatorial. Sendo assim, Símaco tinha a importante missão de estabelecer boas relações com o imperador. Havia não apenas o discurso, mas também certa quantidade de ouro (aurum oblaticium ${ }^{2}$ ) que os senadores ofereciam "voluntariamente" ao imperador. Em Roma, os senadores aguardavam ansiosos pelo regresso de Símaco e por informações de primeira mão.

É estranho ver que um senador tão jovem - Símaco não tinha ainda nem trinta anos - recebesse tamanha honra e responsabilidade. Sogno (2006, p. 6), sem colocar em xeque a capacidade do orador, argui que isso foi possível, em parte, graças ao Prefeito de Roma naquele então, Pretextato, responsável direto pela arrecadação da oferenda de ouro ao imperador e pela escolha do "correto" orador que a levaria. Há de se ter presente que das epistolae de Símaco, várias delas têm Pretextato como destinatário.

Símaco não se limitou a estreitar laços de amizade apenas no Senado. Buscou também amigos na corte imperial. E um de seus principais foi Ausônio, tutor de Graciano, filho de Valentiniano I. Sabe-se que eles trocavam correspondências antes mesmo de Símaco ter ido à Tréveris e que havia entre eles uma mútua admiração. (SOGNO, 2006, p. 6).

A prova de que o panegírico (laudatio) de Símaco dirigido a Valentiniano foi um sucesso, de acordo com Sogno (2006, pp. 8-9), foi o fato do próprio imperador ter solicitado ao orador um segundo panegírico. Símaco é consciente de sua responsabilidade e da honra que lhe é aferida, e expressa esses sentimentos em seu discurso. Consciente de que o objetivo primeiro de uma laudatio é agradar ao público, Símaco expõe que tudo o que anuncia e proclama é verdadeiro, baseado em fatos que vivenciou e também naqueles de que ouviu o testemunho.

Sogno (2006, p. 9) classifica o primeiro panegírico de Símaco a Valentiniano como um encômio biográfico, composição descrita em detalhe no terceiro livro da Institutio oratoria de Quintiliano. Nele, Símaco reconhece e celebra publicamente o estabelecimento da dinastia valentiniana, realizando um resumo dos seus cinco primeiros anos de reinado, desde que tinha sido escolhido pelo exército. O encômio biográfico, como detalha Sogno, requer discorrer também sobre os ancestrais e os descendentes da nova dinastia.

\footnotetext{
2 "Os claríssimos, i.e., os indivíduos de categoria senatorial, tinham ainda que contribuir com o aurum oblaticium, oferecido pelo Senado por ocasião dos aniversários dos imperadores." (SILVA \& MENDES, 2006, p. 212). Isso era parte da reforma fiscal, iniciada por Diocleciano e ampliada por Constantino.
} 
São estratégicas as alusões que Símaco faz do lugar de nascença de Valentiniano e daqueles onde ele acompanhou seu pai em campanhas militares. O futuro imperador nasceu na fria região da Ilíria e acompanhou seu pai no calor escaldante da África. Isso significa não só que ele está preparado para qualquer dificuldade que advir, mas, sobretudo que é um homem que conhece seu reino muito bem, porque já esteve em diversas partes dele. Todas essas dificuldades, unidas aos inimigos enfrentados, the qualifica como a melhor pessoa para reger o Império. (SOGNO, 2006, p. 10). Um cuidado que Símaco tem em sua laudatio é o de reforçar a legitimidade de Valentiniano, sobretudo ao dizer que ninguém protestou quando o elegeram, dando a impressão de que houve um consenso geral no exército. (SOGNO, 2006, p. 12).

O conteúdo dos panegíricos é exagerado e por isso deve-se ter cuidado ao tomálos como fonte histórica. No entanto, nos revelam muito sobre o tempo de Símaco e sobre ele mesmo. No primeiro, dedicado a Valentiniano I, por motivo de seu primeiro lustro no poder, vemos como Símaco enaltece a vida e a obras do imperador, desde sua tenra formação nas diversas partes do Império, seguindo o bom exemplo de seu pai Graciano. Com verbosidade, Símaco atesta que não havia outra pessoa melhor para o posto de imperador que o próprio Valentiniano, superior a qualquer outro líder. Homem valente, assentou-se na parte mais perigosa do Império, Tréveris, e lutou contra o inimigo mais feroz dos romanos, os alamanos. Além de guerreiro é sábio, e prefere defender os interesses do Estado que os seus próprios. É por isso que deixou a seu irmão Valente cuidar sozinho da rebelião de Procópio, uma guerra interna, enquanto ele se dedicava a proteger o Império dos inimigos externos. Foi um imperador que preferiu o bem comum ao de sua própria família. Realizou obras incríveis.

O começo do segundo panegírico a Valentiniano indica sua razão de ser: o terceiro consulado do imperador, ao lado de seu irmão Valente, em 370. Símaco, estrategicamente, revela que irá relatar apenas alguns acontecimentos, sem exaustão. Deixará todos os outros feitos não mencionados para que sejam cantados pelos poetas. Parabeniza ao imperador por ser sua fonte de inspiração e o restaurador da liberdade de expressão. Ao mesmo tempo que Símaco preza ao imperador, por ter dado assunto que fosse cantado e escrito, como suas grandes vitórias sobre os alamanos, ele também lembra o imperador de que sem esses oradores e poetas, há o silêncio, e que o silêncio é o pior inimigo da grandeza. (SOGNO, 2006, p. 12).

Símaco se dedica basicamente a enaltecer o imperador por suas conquistas e fortificações ao longo do Reno, e de que se impressionou ao ter visto as mesmas pessoalmente. Enaltece-o por seu terceiro consulado, mas, sobretudo se centra em seus avanços militares. Entre outras exaltações, Símaco o parabeniza por ser exemplo de governante ideal, que é amado e temido por seu povo. Também o parabeniza por haver aceitado o Império de forma relutante. (SOGNO, 2006, p. 14). Na verdade, Símaco exaltou muito mais as fortificações erguidas por Valentiniano do que suas batalhas contra os bárbaros. Sogno (2006, p. 15) pensa que isso se deve principalmente pelo acontecido com Siágrio, único sobrevivente de uma batalha, que foi considerado um desertor pelo imperador. E isso aconteceu exatamente quando o orador se encontrava na corte.

O segundo panegírico dedicado também a Valentiniano I tinha por motivo a designação do imperador para o seu terceiro consulado, que ele havia recebido como um reconhecimento por seus feitos recentes. Sendo assim, o panegírico deveria se centrar em suas atividades recentes, as quais lhe fizeram merecedor do terceiro consulado. Símaco inicia dizendo que o consulado era uma recompensa insuficiente para Valentiniano, comparado com tudo o que perpetrou no Reno. Mas como não há algo 
maior que eles possam ofertar, Símaco solicita ao imperador que se contente com o melhor presente e honra que o Senado lhe pode oferecer. E a partir de então, o orador narra as atividades bélicas de Valentiniano contra os alamanos, e suas construções ao longo do Reno. Em um determinado momento, Símaco o elogia por haver restaurado a liberdade de expressão no Império. Termina exaltando sua sobriedade.

No panegírico de Símaco dedicado a Graciano, vê-se claramente como ele se dirige ao jovem imperador como a esperança de Roma. Durante todo o discurso, o orador enfatiza sua juventude, enaltecendo-a. Sogno acredita que essa insistência seja uma forma de favorecer a aceitação do imperador, possivelmente criticado pela aristocracia romana por sua pouca idade. (SOGNO, 2006, p. 18). Como recompensa por sua performance na corte, Símaco recebeu o título honorífico de comes tertii ordinis, e três anos depois, em Roma, recebeu o proconsulado da África (373-374).

O panegírico ao menino Graciano talvez tenha sido o mais difícil para Símaco elaborar. Devido a sua pouca idade, objetivamente não havia feitos grandiosos do qual ele fosse sujeito. No entanto, Símaco surpreendeu mesmo assim. Vê em Graciano o início de uma nova época, porque é um imperador ainda menino, e sendo assim, estará bem treinado em todos os campos. Seu louvor se centra, então, na juventude do imperador e em seu governo ao lado de seu pai Valentiniano e de seu tio Valente. Aos bárbaros não lhes restará mais do que a escravidão, e eles já sabem disso.

\section{OS DOZE PANEGÍRICOS LATINOS}

Tendo em vista as três orationes mencionadas, podemos fazer uma breve análise dos famosos doze panegíricos latinos, com o intuito de entender melhor as diversas asserções simaquianas, bem como seu estilo. Susanna Morton Braund (2005, pp. 90-91) descreve que de forma convencional a oratória grega foi divida em três tipos: discurso forense, deliberativo e epidíctico. O primeiro, também chamado de judicial, eram aqueles proferidos nos tribunais, no fórum; os discursos deliberativos eram aqueles proferidos diante do Senado ou de uma assembleia do povo; e os discursos epidícticos eram aqueles escritos para uma comemoração especial. Este último, para Braund, se revestiu de especial importância durante o principado, como panegírico (elogio):

Uma das coisas mais importantes para um aristocrata romano era o reconhecimento pelas pessoas ao seu redor de seu valor público e permanente - sua auctoritas e sua dignitas. Idealmente, isso seria celebrado em panegírico - isto é, louvor escrito em prosa ou verso. ${ }^{3}$ (2005, p. 110).

O panegírico era um elemento central na política romana e na vida pública sob o Principado - e já o era há muito tempo. De fato, alguns dos nossos mais antigos textos latinos sobreviventes, os epitáfios aos membros da família Cipião que datam do terceiro e segundo séculos A.E.C. (Scipionum elogia), são os louvores (póstumos) dos grandes homens. ${ }^{4}$ (2005, p. 112).

\footnotetext{
3 "One of the most important things for a Roman aristocrat was the recognition by people around him of his public worth and standing - his auctoritas and his dignitas. Ideally this would be celebrated in panegyric - that is, praise written in prose or verse."

4 "Panegyric was a central element in Roman politics and public life under the Principate - and had been so for a long time already. In fact, some of our earliest surviving Latin texts, the epitaphs to members of
} 
Ainda sobre o panegírico e sua difusão durante este período do Império Romano, Mitchell (2015, p. 19) o relaciona à natureza autoritária do mesmo. Segundo ele, a dissidência aberta não era tolerada, e isso se vê pelos extremos dos discursos, que são de louvor ou vituperação, mas raramente se encontram num meio termo. Apesar de parecerem pouco confiáveis, o autor defende a utilização de panegíricos e poemas como fontes históricas para o período, alegando que seus exageros, omissões e estilos retóricos expressam de forma crítica muito daquele momento. Segundo Mitchell, as obras mais significativas neste gênero são os doze panegíricos latinos ${ }^{5}$ :

\begin{abstract}
As obras-chave neste gênero são os doze panegíricos latinos, que provavelmente foram compilados pelo orador gaulês Pacato, e foram prefaciados pelo longo panegírico de Plínio, o Jovem para o imperador Trajano (I). Além do trabalho do próprio Pacato de 389 em louvor a Teodósio I (II), este inclui discursos a Maximiano em 289 (X, de Cl. Mamertino, o Velho) e 291 (XI), a Constâncio, pai de Constantino, em 296 e 298 (IX), para o casamento de Constantino e Fausta em 307 (VII), a Constantino em 310 (VI), 312 (V), 314 (XII), e 321 (IV, de Nazário) e a Juliano em 362 (III, de Cl. Mamertino, o Jovem em sua própria nomeação para o consulado). ${ }^{6}$
\end{abstract}

Mitchell (2015, p. 4) realça que, conforme o Império crescia, foi se dando cada vez mais ênfase à religião do Estado. Acreditava-se que ele era mantido devido ao apoio dos deuses e os imperadores romanos, que em parte controlavam as atividades religiosas em seus territórios, eram vistos como aqueles que mantinham o pacto de paz com os deuses, a pax deorum. E segundo Mitchell, todos os meios de propaganda estavam imbuídos desta ideologia, inclusive os discursos panegíricos.

Braund $(2005,129)$ especifica que o cônsul Plínio entregou seu panegírico ao imperador Trajano no início de seu reinado. Era um discurso de gratidão, onde ele aproveita para contrastar a imagem do bom Trajano com a do mau Domiciano, imperador de 81 a 96 E.C. Para Braund (2005, p. 130):

Este texto revela dois modelos contrastantes de patrono ou imperador - e, afinal de contas, o imperador era apenas o patrono mais poderoso em Roma. O bom patrono ou imperador é marcado por sua abertura, acessibilidade, e atitude amigável e tolerante. O mau patrono ou imperador é marcado pelo abuso tirânico de seus poderes para tomar decisões de vida e morte sobre todos ao seu redor, do menor escravo ao senador mais eminente. A celebração do bom modelo e a condenação do ruim encontram-se em toda a gama de textos da literatura latina, incluindo poesia épica e pastoral, poesia lírica e elegíaca, sátira e epigrama, historiografia, oratória e romance. Isso não nos deixa duvidar de que o modo como um homem poderoso se comportava com seus

the Scipio family dating from the third and second centuries BCE (the Scipionic elogia), are the (posthumous) praises of great men."

${ }^{5}$ Ver também, BERRY, D. H. Oratory. In: HARRISON, Stephen (ed.). A Companion to Latin Literature. Oxford : Blackwell, 2005, pp. 267-268.

6 "Key works in this genre are the twelve Latin panegyrics, which were probably compiled by the Gallic orator Pacatus, and were prefaced by the younger Pliny's lengthy panegyric for the emperor Trajan (I). Apart from Pacatus' own work of 389 in praise of Theodosius I (II), this includes speeches for Maximianus in 289 (X, by the elder Cl. Mamertinus) and 291 (XI), for Constantius the father of Constantine in 296 (VIII) and 298 (IX), for the marriage of Constantine and Fausta in 307 (VII), for Constantine in 310 (VI), 312 (V), 314 (XII), and 321 (IV, by Nazarius), and for Julian in 362 (III, by the younger $\mathrm{Cl}$. Mamertinus on his own appointment to the consulship).” 
pares e seus subordinados era crucial para sua posição social e reputação política. $^{7}$

Bruce Gibson (2005, p. 72) critica a postura deste gênero por não se envolver abertamente com a política atual de seu tempo, senão de modo indireto, e o panegírico modelo não foi a exceção: "Mesmo o Panegírico de Plínio, um discurso em louvor ao imperador Trajano dado por ocasião de seu consulado em setembro de 100 E.C., oferece sua crítica de governo indiretamente, através da estratégia de atacar o principado de Domiciano". 8

\section{CONSIDERAÇÕES PARCIAIS}

As condições do discurso representavam um novo momento para o Império. De acordo com A. D. Lee (2013, p. 1) foi por meados do século IV que o Império Romano havia alcançado quase tanto território quanto durante o século II, período conhecido pelo auge do poder romano. Foi o período dos imperadores guerreiros, que se viram forçados a se retirar dos confortos de Roma para proteger suas fronteiras. (LEE, 2013, p. 5). Roma foi substituída como residência imperial por Tréveris, Milão, Sirmio e Antioquia. Com a criação de Constantinopla por parte do imperador Constantino, essa situação só se agravou. De qualquer forma, o tema que domina o século e que dominou os discursos traduzidos de Símaco foi a história militar. (MITCHELL, 2015, pp. 11-12).

Não é um Império em decadência, mas sim um momento de transição. Mitchell (2015, p. 56) se dá conta de como, por exemplo, Diocleciano, Joviano e Valentiniano vieram de origens semelhantes. Eram todos militares de meia idade nascidos nas províncias da Ilíria, o que plasma uma mudança no eixo do poder. Mitchell (2015, pp. 5657) frisa como desde a ascensão de Diocleciano em 284 até a morte de Teodósio I em 395, o Império foi governado por esses imperadores guerreiros, que aniquilavam inimigos internos e externos. O Estado estava centrado em guerras e batalhas. Calcula-se que mais de dois terços de seu orçamento anual eram gastos em atividades militares, atividades das quais os imperadores participavam pessoalmente.

Símaco soube valer-se da situação para estreitar laços com a corte e obter ascensão política. Esse período foi especial também por sua produção literária e pela quantidade de escritos que sobreviveu ao tempo. Segundo O’Donnel (2015, p. 161), há mais literatura latina que nos chegou entre 350 e 450 do que de qualquer outro período, mais até mesmo que a época de ouro latina, entre o final da República e começo do Império. ${ }^{9}$

\footnotetext{
7 “This text reveals two contrasting models of patron or emperor - and, after all, the emperor was just the most powerful patron in Rome. The good patron or emperor is marked by his openness, accessibility and friendly and tolerant attitude. The bad patron or emperor is marked by his tyrannical abuse of his powers to make life and death decisions about everyone around him, from the lowest slave to the most eminent senator. Celebration of the good model and condemnation of the bad model are found in the entire range of texts of Latin literature, including epic and pastoral poetry, lyric and elegiac poetry, satire and epigram, historiography, oratory and the novel. This can leave us in no doubt that how a powerful man behaved towards his peers and his subordinates was crucial to his social standing and to his political reputation."

8 “Even Pliny's Panegyricus, a speech in praise of the emperor Trajan given on the occasion of his consulship in September AD 100, offers its critique of rulership indirectly, through the strategy of assailing the principate of Domitian."

9 "We have more surviving Latin literature from this century between 350 and 450 than for any comparable period before that, including the more famously golden age of Caesar, Cicero, and Vergil."
} 


\section{REFERÊNCIAS DOCUMENTAIS}

MEYER, Gulielmus. Q. Aurelii Symmachi Relationes. Leipzig: Teubner, 1872.

QUINTILIANI, M. Fabi. Institutiones oratoriae libri duodecim. Edited by M. Winterbottom. Oxford: Clarendon Press, 1970.

SYMMACHUS, Quintus Aurelius. Aurelii Symmachi quae supersunt. Otto Seeck (ed.). München: Monumenta Germaniae Historica, 1883.

. Oration I - translation, commentary, bibliography. Tradução de Barbara Saylor Rodgers. Burlington: The University of Vermont, 2015a. Disponível em:<https://www.uvm.edu/ bsaylor/rome/Symmachus1.pdf >. Acesso em: 19/10/2016.

. Oration II - translation, commentary, bibliography. Tradução de Barbara Saylor Rodgers. Burlington: The University of Vermont, 2015b. Disponível em:<https://www.uvm.edu/ bsaylor/rome/Symmachus2.pdf >. Acesso em: 19/10/2016.

Oration III - translation, commentary, bibliography. Tradução de

Barbara Saylor Rodgers. Burlington: The University of Vermont, 2015c. Disponível em:<https://www.uvm.edu/ bsaylor/rome/Symmachus3.pdf >. Acesso em: 19/10/2016.

Q. Aurelii Symmachi Octo orationum ineditarum partes. Edição, introdução e comentários de Angelo Mai. Milão: Biblioteca Ambrosiana, 1815.

\section{REFERÊNCIAS BIBLIOGRÁFICAS}

BRAUND, Susanna Morton. Latin Literature. London: Taylor \& Francis, 2005.

GALLEGO, José Antonio Valdés. Informes - Discursos. Introducciones, Traducción y notas de José Antonio Valdés Gallego. Madrid: Editorial Gredos, S. A., 2003.

GIBSON, Bruce. The High Empire: AD 69-200. In: HARRISON, Stephen (ed.). A Companion to Latin Literature. Oxford : Blackwell, 2005.

LEE, A.D. From Rome to Byzantium AD 363 to 565 - The Transformation of Ancient Rome. Edinburgh: Edinburgh University Press, 2013.

MITCHELL, Stephen. A History of the Later Roman Empire, AD 284-641. Oxford: Blackwell, 2015.

O'DONNELL, James J. Pagans: the end of traditional religion and the rise of Christianity. New York: HarperCollins, 2015.

SILVA, Gilvan Ventura \& MENDES, Norma Musco. Diocleciano e Constantino: a construção do Dominato. In: SILVA, Gilvan Ventura \& MENDES, Norma Musco 
(org.). Repensando o Império Romano - Perspectiva Socioeconômica, Política e Cultural. Rio de Janeiro: Mauad, 2006, pp. 193-221.

SOGNO, Cristiana. Q. Aurelius Symmachus: a political biography. Michigan: Michigan Press, 2006. 